\title{
Factors influencing Intensive Care Units nurses in end-of-life decisions*
}

\author{
Fatores que influenciam os enfermeiros de unidades de \\ terapia intensiva nas decisões de final de vida \\ Factores que influencian a los enfermeros de unidades de \\ cuidados intensivos en las decisiones de final de vida
}

Michelle Freire Balizaํㅜ, Regina Szylit Bousso², Kátia Poles ${ }^{3}$, Maiara Rodrigues dos Santos ${ }^{1}$, Lucía Silva ${ }^{2}$, Maria Cristina Paganini ${ }^{4}$

\author{
* Extracted from the project: “ $\mathrm{O}$ envolvimento \\ dos enfermeiros nas tomadas de decisão \\ relacionadas às situações de final de vida: um \\ estudo transcultural", Escola de Enfermagem, \\ Universidade de São Paulo, 2013. \\ ${ }^{1}$ Universidade de São Paulo, Escola de \\ Enfermagem, Programa de Pós-Graduação \\ Interunidades de Doutoramento em Enfermagem, \\ São Paulo, SP, Brazil. \\ ${ }^{2}$ Universidade de São Paulo, Escola de \\ Enfermagem, Departamento de Enfermagem \\ Materno-Infantil e Psiquiátrica, São Paulo, SP \\ Brazil. \\ ${ }^{3}$ Universidade Federal de São João Del-Rei, São \\ João Del-Rei, MG, Brazil. \\ ${ }^{4}$ Universidade de Tuiuti, Tuiuti, PR, Brazil.
}

\section{ABSTRACT}

Objective: To identify the factors that influence the Intensive Care Unit nurse in the decision-making process in end-of-life situations. Method: Ethnographic case study, which used the theoretical framework of medical anthropology. Data were collected through semi-structured interviews with 10 nurses. Results: The inductive thematic analysis enabled us to identify four themes: The cultural context of the Intensive Care Unit: decision-making in situations of end-of-life; Beliefs and subjectivity of care in end-oflife situations; Professional experience and context characteristics of end-of-life care situations; and Humanization practices in end-of-life situations: the patient and family centered care. Conclusion: Professional maturity, the ability to transmit information and the ability to negotiate are directly related to the inclusion of nurses in the decision-making process.

\section{DESCRIPTORS}

Terminally Ill; Intensive Care Units; Nursing; Decision Making; Culture; Anthropology. 


\section{INTRODUCTION}

A remarkable and historical event that changed the way of dealing with the phenomena related to the health-disease process is represented by the revolution instituted by Descartes, who established the dichotomy between mind and body. With Cartesianism, the view on the human being became fragmented and focused on the body. This has made the health-disease process to become valued and recognized only in the biological aspect of individuals, and gradually the sociocultural sphere of individuals has been ignored in health practices ${ }^{(1)}$. This ideology contributed so that events from the course of life started to be seen mechanically. Health practices in this context became reduced to interventions in the biological sphere. This culminated in the establishment of the biomedical model; thus, medicine has become indifferent to the trajectories of individuals, to their will, and to their anguish and death ${ }^{(2)}$.

The medical dominance on life events of individuals lead to the term medicalization of life $^{(3)}$. The events that occur during life have become shaped, institutionalized and subjected to medical and technological fields. In this context, death, as a course of life event is seen as a defeat, the end in itself and a total failure of the body $y^{(4)}$.

Nurses who deal with the situations of the end-of-life, while bio-social subjects, possess unique sociocultural aspects that reveal different values, ways of acting, thinking, feeling and interpreting death based on their worldview, arising from relations and established interactions with people and the environment where they live and act $^{(5)}$. Thus, it is important to recognize that death and decision-making processes are mediated by the sociocultural contexts and also by personal and family history of professionals, since different cultures embody death differently and prepare representations consistent with the context. We can say that humans are a reflection of the cultural environment where they were socialized ${ }^{(6)}$. From this perspective, values and cultural aspects of individuals are involved in decisions that occur in the practice field, in care relations and the way that health professionals deal with death. Thus, the practices and decisions that occur in the context of end-of-life care are permeated by culture( ${ }^{(3)}$.

We can say that decision-making is an essential process of human nature; therefore, it is related to different notions of culture. Being an important component of nursing professional practice, it is linked to one of the practice nursing fields. The concept decision-making can be defined as the selection of obvious alternatives or acceptable solutions. The attributes of the decision-making concept is related to the need to make a deliberate choice between two or more options, which commits the individual to a path of actions and expresses the expectation range of one or more specific objectives (t).

In the context of Intensive Care Unit (ICU), nurses are challenged to participate in decision-making related to patient and family care, facing complex situations, how to maintain or discontinue life support. Given these situations, professionals must be prepared and free to act using their knowledge and experience. In this sense, many deaths that occur in the ICU are preceded by decisions related to the restriction or suspension of life support measures ${ }^{(8)}$.

These decisions, in particular, are more complicated because they involve life support treatments that often do not represent benefits to the patient and, when applied, rise doubts in the multidisciplinary team, for example, which decisions must be made regarding the care provided to the patient and his/her family, who are the professionals who should participate in this process and the role of each professional in these situations. The above confirms the importance of performing this study, which aimed to identify the factors that influence ICUs nurses in the decision-making process in end-of-life situations.

\section{METHOD}

This is a study of qualitative approach, and the methodological framework of the study is ethnographic case and the theoretical framework is medical anthropology. Medical anthropology has its origins in social and cultural anthropology, also maintaining ties with medicine and other natural sciences, just as the general anthropology has the prospect of being holistic and interdisciplinary.

Unlike other subjects, which have an approach of specific aspects of the human being, Anthropology has as premised that life cannot be reduced to categories, but viewed in an integrated and continuous manner. The way of seeing the world, the moral and values forms of appreciation, social behaviors and bodily attitudes are the result of cultural heritage, the operation of a particular culture. Thus, culture, in brief, is the shared and learned knowledge of a society ${ }^{(6)}$.

Cultural concepts of health-disease processes are subsidized by the medical anthropology. It is important for the field of health that the end-of-life experiences and decisionmaking during this process are studied based on anthropological theoretical framework.

Among the types of ethnographic approach, the case study was chosen to give voice to their lived experiences, which allowed us to capture the meanings that individuals attribute to their own experience within the sociocultural system in which they live $e^{(9)}$. In the case study, attention is focused on what we can learn about what is common, particular and unique to a specific phenomenon ${ }^{(10)}$.

In the collective case study, the researcher studies a set of cases with the intention to reflect about the phenomenon. Employing a case study in the anthropological perspective means defining an area of knowledge in which the social and the cultural dimensions are articulated ${ }^{(11)}$.

Sampling was intentional as inclusion criteria ${ }^{(12)}$, which is composed by 10 nurses from the cities of Sao Paulo and Curitiba, who worked for at least one year at the ICU, regardless of additional training, the training time and the institutional bond. The first collaborator became the main informant and indicated other nurses who worked in adult ICU of public and private hospitals.

We used, as data collection method, the participant observation and semi-structured interview ${ }^{(12-13)}$; throughout the whole process, both during the observation as during the phase of interviews, field notes were made to record ob- 
servations of the researchers, the relevant data of the study and the non-verbal language. This whole process took place in the period between August and December 2012, from two guiding questions: 1 - Tell me about your experience in the process of decision-making in end-of-life situations. 2 - Which factors do you think influence this process? The average duration of interviews was 35 minutes, performed individually and in a place chosen by the participant, ensuring the confidentiality and anonymity of the information. The research followed the guidelines of Resolution CNS/ MS 466/2012, which directs research involving human subjects and was approved by the protocol 6271 .

Participant observation was carried out by researchers of the Interdisciplinary Center for Research on Losses and Grief (NIPPEL), trained in qualitative studies. Individual interviews were digitally recorded, transcribed in full and submitted to inductive thematic analysis of the data ${ }^{(14)}$. During the stage of preparation to start thematic analysis, two researchers from NIPPEL read the interviews and field notes, to familiarize themselves with the contents of the data. In case of doubt or conflicted themes, a third researcher from the group was consulted and when consensus was reached, the data were presented to the Research Group.

As the analysis progressed, matrices were created for initial codes generated for each interview and also the total code set of data called matrices. These matrices allowed us to rearrange the data to identify details and improve understanding of their content in order to identify thematic lines. As they progressed in the interpretation of data, new questions about the content of data emerged and, consequently, new understandings were reached ${ }^{(15)}$. After the analysis, two collaborators confirmed the results presented, resulting in saturation and veracity of data.

\section{RESULTS}

Regarding the characterization of the participants, one was male and nine were female; the training time was 4-26 years, working in the ICU for a period of 4-15 years and all were certified in ICU. At the time of the interviews, six nurses were working in private hospitals and four in public hospital. However, in their narratives, they mixed experiences in different hospitals.

The inductive thematic analysis revealed four themes that represent the factors that influence ICU nurses in the decision-making process in end-of-life situations and that will be presented below.

\section{THE CULTURAL CONTEXT OF ICU: DECISION-MAKING IN END-OF-LIFE SITUATIONS}

The ways to deal with death within the context of ICU are related to beliefs in the way that Brazilians deal with it. Death seems to be a veiled subject within the hospital setting.
Brazilians are extroverted people. We like car- nival, soccer, parties, laughing, playing! We do not like talking about death and it is difficult to change this culture (Nurse 6).

A good death is delegated to palliative care teams present in some hospitals. However, nurses exacerbate medical power, with respect to offering good death when they call for palliative care.

Nurses, especially in private hospitals, expressed the difficulty in dealing with end-of-life situations, saying it is not common for doctors to call the palliative care team. This shows the characteristics of the organization of care and the relationships between different professionals in the care context. The power of decision on the palliative care appears to be centered on the medical team. However, they believe that patients and family members who have had this kind of care and were followed by palliative care, received better follow-up with less suffering.

What I realize is that, here, in this hospital, it isn't very common for people to be followed up by palliative care, but [for] patients and family members who I interacted with, who were followed by palliative care, it was much easier to deal with and pass away (death) experience was different, and here, unfortunately, it is not a very common thing. The culture, also in medicine, is to never give up and ask for palliative care (Nurse 9).

Thus, in the context of ICU, this scenario is even more challenging; health professionals have difficulties to incorporate end-of-life care and the philosophy of palliative care in assisting the patient and his/her family. However, they believe that in Brazil, there is still no appropriate structure for palliative care demands, both from a quantitative and qualitative point of view.

ICUs appear to be in a cultural changing process in which humanization wants to take the place of impersonal deaths, which are also isolated from the family. Although the practice of nursing is seen by the nurses as a practice that considers not only the practice dimension of care, but also the dimensions of knowledge, it is noted that these professionals also work supported by their subjectivity and cultural values and in the recognition of cultural sphere and individuals subjectivity who are involved in this process.

The family member doesn't know what to do, if
they should cry, or hold hands, it is a very diff-
cult moment. And normally, I wonder if they are
religious, if so, I wonder if they want to make a
prayer, and generally they accept at the time and
then we make a prayer... So this practice seems to
guide the family (Nurse 10).

When nurses find no support or approval of the medical team to call the palliative care service, they feel weak to work alone. They believe they do not have proper training to deal with patients and family in end-of-life; still, they seek to play an educational role with the family such as clarifying that the patient is out of healing possibilities. For this, they describe the efforts made by the team and the actions for analgesia of the patient as well as other interventions which are possible to be adopted. 
Nowadays, when we do not have the support of palliative care, I think I have an educational role with the family: I try to explain what is happening with the patient, what are the interventions that we are doing to alleviate the suffering of the patient (Nurse 10).

Nurses need to maintain a good relationship with the medical team and be pro-active about problems and opportunities, to start a conversation with physicians in order to suggest palliative care to the patient and his/her family. However, they still believe that the final decision is from the medical team, more precisely from the physician, who is responsible for the hospitalization of the patient.

I said I thought that the family needed support,
because they were demonstrating it physically,
they were very shaken, emotionally, and they
needed someone to help at that time. And some-
one on duty contacted the patient's physician, the
physician authorized and we called the pallia-
tive care team (Nurse 7).

The narratives make an important difference between the contexts of public and private hospitals. In private hospitals, there is more participation and family involvement in the decision-making process in end-of-life situations, compared with public hospitals. However, the autonomy of nurses of private hospitals in this process appears to be limited; these professionals feel intimidated and subordinated to the medical staff and have little or no control on the decision-making in end-oflife situations. In public hospitals, nurses have more openness for dialogue and discussion with other professionals, especially physicians and interns.

\section{I think that in the public hospital, nurses have more autonomy, we have a much larger work- load, you deal with lack of material, lack of professional... But on the other hand you have greater openness from other teams (Nurse 8).}

However, even if the professional has competencies and skills to actively participate in end-of-life decisions, in some contexts, nurses feel disempowered to provide care and interventions to alleviate the suffering and comfort the family - especially when the medical team do not share the patient's prognosis in a clear and transparent manner with family members.

$$
\begin{aligned}
& \text { It's hard, it's hard, because he (the accompany- } \\
& \text { ing family member) is absolutely sure that the } \\
& \text { patient will be discharged, that the patient will } \\
& \text { go home and we are absolutely sure that he will } \\
& \text { not. It is a great responsibility... Sometimes we } \\
& \text { have a great desire to talk and make it clear, but } \\
& \text { we cannot, we have to be very careful, other- } \\
& \text { wise there might be a conflict with the opinion } \\
& \text { of other professionals (nurse 9). }
\end{aligned}
$$

\section{BELIEFS AND SUBJECTIVITY IN CARE IN END-OF-LIFE SITUATIONS}

Personal beliefs are their own values, beliefs and convictions that nurses have about life and death. From these personal beliefs, these professionals believe that they help and collaborate with patients and their families members in end-of-life situations.

Nurses' beliefs have strong influence on the meanings attributed to their experiences when facing end-of-life situations of patients and their family members. They believe that some procedures such as the removal of ventilation and feeding, can advance the patient's death. Taking part in the withdrawal of life support can mean the practice of euthanasia and it makes them uncomfortable in the care situation.

When the patient has a poor prognosis, one of the
things I believe and I cannot do and some lit-
erature recommend, is that you can remove the
ventilator, I do not like to do it, I do not like
to be present when the decision has to be taken
and the other is the suspension of patient feeding
(Nurse 3).

Religiosity, spirituality and personal values influence nurses in dealing with end-of-life situations of patients. The data demonstrated that these personal beliefs can help them experience a more confident process of end-of-life care provided to the patient and his family.

\section{I bring a lot of personal experience and the faith that I have (...). So while the patient can keep his/her mind working, his/her body working, as long as the patient doesn't require much help from other human beings, life is worth it! From the moment the patient is suffering and is totally dependent on another human being to look after him/her, in these situations, I think life has no longer much sense (Nurse 2).}

Personal history and background that each nurse brings during this experience of end-of-life can be confronted with opinions, values and knowledge of other health professionals. However, the way nurses experience this process can undergo change, according to his/her professional experience, autonomy and competence in relationships with other professionals, family members and patients themselves.

\section{Professional experiences AND CONTEXt CARe CHARACTERISTICS IN END-OF-LIFE SITUATIONS}

This theme presents a set of knowledge, skills, behaviors and abilities that allow nurses, according to professionals, to obtain success in carrying out certain activities for the effective participation of nurses in decision-making processes in end-of-life situations.

Nurses emphasize the importance of years of experience in the acquisition of knowledge and maturity to handle situations involving decision-making in end-of-life situations. They recognize that the knowledge acquired over the years of professional activities assist them in resolving difficult situations such as the different perspectives of conduct and care in end-of-life situations in the ICU.

Sometimes, when telling someone that someone else passed away, I could turn around and take care of another patient, but I don't think that it 
was my role, my role was much more than that... So I believe that there was a combination of factors, of professional maturity in view of a whole, the belief that this moment really was a final moment and it needed to be very precious, very well maintained and that the failures of the professionals at that time, could generate, especially in the family, unrecoverable traumas (Nurse 5).

Nurses, especially the younger ones, feel unprepared and unable to comfort the family or talk about the limiting process of life support and the end stage of the disease. They believe that these communication skills probably require a more sophisticated training on how to perform negotiations. Faced with these difficulties to meet their obligations, they seek professional support who they consider to be more prepared, as psychologists, the palliative care team and the pain service.

It is hard to talk to the family, explain the severity... We say: It is serious... But it seems that the ears are closed. I have much trouble with it, in separating things. Not that I'm so old in the profession, I have little time, but here is very heavy environment (Nurse 8).

For nurses, there is lack of preparation to deal with end-of-life situations of patients. In private hospitals, the team of palliative care and pain service act as support and are reference for nurses in these situations. Nurses observe the palliative care team behavior to become more skilled in their actions with the patient and family. However, they reported that these services are not easily accessible.

\section{I try my best so that family and patients are cared and welcomed, sometimes I feel impotent, because they have various processes so that we can do it; I am speaking specifically of palliative care that is my reference in this hospital (Nurse 7).}

The idea that nurses are committed to make a difference in patient care and family in end-of-life situations is expressed by them. Nurses, even with all difficulty and lack of preparation to deal with these situations, understand that they have a duty to care for the patient and family and that something must be done to reduce the suffering and deprivation that the family is living in this period.

\section{HUMANIZATION PRACTICES IN END-OF-LIFE SITUATIONS: THE PATIENT AND FAMILY CENTERED CARE}

Nurses clearly expressed their role in end-of-life situations when the patient has an incurable disease. They believe it is their moral obligation to ensure the peace of the patient and family during the process of dying and comfort for families. To achieve these goals, they allow visitation schedules for family members and religious people, providing alternative diets, maintaining careful hygiene and pain relief.
(...) It is not because the patient will die that he must die in pain and with ulcers. Changing po- sitions, hygiene, program hygiene, is to keep the patient comfortable, in order to enable the family to stay with him as long as possible (Nurse 6).

End-of-life situations put nurses in front of family suffering, which makes them appreciate the family-centered care. Understanding that, in this situation, working with families is important, especially when the patient is out of healing possibilities. The paradigm shift, the patient's cure for the care and relief of patient and family suffering, is a slow process and depends on the nurses' initiatives. Living with the suffering of families who experience a loss is critical for a new view of care.

\section{One thing I've always done is, regardless of public or private hospital, that this family was sure that everything was done to the patient (Nurse 5).}

In care and in decision-making at the end-of-life, nurses need to believe that the procedures and the assistance offered were the best possible. For the interviewed nurses, it is their moral obligation that the patient had a dignified endof-life, with relief from the physical and emotional suffering. Also considering fundamental to the family, knowing that all the best care was provided to the patient. They believe that this is the way to help the family in the patient's death process.

\section{The certainty of knowing that all the best care was provided for that person that helshe loves, gives them a very good sensation. And I think that everything we, professionals from health- care field, can do to have that final answer should be done (Nurse 4).}

\section{DISCUSSION}

Through inductive analysis, based on an anthropological perspective, it was possible to reach an innovative interpretation of the data from this research, which identified the factors that influence the nurses in the decision-making process in end-oflife situations from adult ICU.

In end-of-life situations, particularly those in which the patient is considered, by the nurse, out of healing possibilities, the role of ICU professionals change; that is, the aggressive care should lead to end-of-life care, guided by the principles of palliative care ${ }^{(16)}$. This paradigm shift, from the cure for the care and relief of patient suffering and their families, it is a slow, stressful process and therefore full of ambiguities and anxieties experienced mainly by nurses working in the ICU. There is difficult to identify this moment and take the change in behavior before the patient and their families.

While the nurses of the palliative care team typically receive specialized support to deal with these end-of-life situations, intensive care nurses are often not prepared to provide assistance to the patient and his/her family(16). Although the professional maturity and years of ICU experience are key factors to make a difference in the care and relief of patient and their family members suffering ${ }^{(17)}$, nurses, in their narratives, report that there is not a team effort and transparent discussions to implement the philosophy of palliative care in the context of ICU and point to the absence as an aspect that hinders their greater participation and also as a component capable of generating more suffering to 
the patient and family. This shows how care practices are organized in the context of ICU and cultural and subjective aspects are present among health professionals, patients and family.

Despite their difficulties and little preparation to deal with decision-making in end-of-life situations in ICU, nurses use their studies and their knowledge, acquired in practice and professional career, to qualify the family; that is, they become facilitating agents and educators in these end-of-life conditions ${ }^{(17)}$.

Although, it has been previously indicated in the literature that nurses should be involved, but indirectly, in endof-life situations, the recent literature indicates that nurses are more engaged with the role of advocating in favor of the patient and family in the end-of-life process. Nurses interpret and explain to the family the prognosis of the patient and what is happening to him/her; accordingly, the family is happier and becomes able to advance in their acceptance and decision-making ${ }^{(18)}$.

However, our study shows that family feel lack of openness and precise and clear dialogue in the relationship with nurses. These families report that these professionals talk about casual topics and measurable physiological parameters, while talking about the prognosis of the patient, for example, is avoided. Thus, family members interviewed in the study, believe that nurses are subordinates and representatives of the medical team ${ }^{(19)}$. Comparable to our results, nurses, mainly from private hospitals realize that, at times, they do not share all the information they know; they feel that the medical team does not authorize them to make the patient's prognosis clear to the family.

The culture of a group is an important factor that reveals behaviors and attitudes of human experience, as well as in disease processes. The habits, customs, spirituality and belief, expressed by the culture of a group, show different ways of thinking of individuals that health professional is not always familiar ${ }^{(20-21)}$. Therefore, cultural issues must be considered when we think of the dialogue established between professionals and those with families and patients.

Through established relationships with patients and their families, nurses believe that the family is an integral part of care in ICUs, especially in end-of-life situations. In this research, the nurses described how, over time, they became sensitive to the suffering of the family who is losing one of its members, and with this awareness, discovered the importance of family care.

The Institute for Patient and Family-Centered Care (IPFCC) provides directions to advance in understanding, comprehension and practice of this patient and family centered care in hospitals and other healthcare facilities. These directions have four key concepts: Respect and dignity; Sharing information; Participation and collaborative care ${ }^{(22)}$.

This care is an approach to the planning, delivery and evaluation of health care services, which is based on mutually beneficial partnerships among health professionals, patients and families. Thus, these cares redefine the relationships in healthcare.
Health professionals who offer patient and family centered care recognize the vital role that families have to ensure the health and well-being of patients of all ages. They recognize that the emotional and social support are an integral part of health care, recovering and restoring dignity and control to family ${ }^{(22)}$. Surprisingly, our results point to the interest of nurses to include the family in their care, and the statements show that they respect, albeit informally, the concepts proposed by IPFCC.

The humanistic paradigm of care recognize, as one of its principles, that the patient is a relational being; this means that care should not be based on linearity which means that the health professional is the holder of knowledge and their position is reduced to the transmission of information, and the only one who has the power of decision ${ }^{(4)}$. Thus, care practices in end-of-life situations guided by a humanistic paradigm enable the health professional to correspond the individual needs of patients and their families, creating space for the manifestation of their desires, anxieties and wishes. Giving voice to patients and families in order to promote humanized care shown challenging for the nursing staff, however, possible when there is room for exchanges and interactions ${ }^{(23)}$.

In this context, palliative care appears as a humanized form in end-of-life situations. Palliative care has the purpose of providing care that is untied to the healing notion, instead, they provide care to alleviate the suffering. Palliative care appears to counteract the technological and institutionalized practice, in which the patient and the family are excluded from the decision-making process. This type of care proposes a new social representation of death, which is made possible through innovative forms of relationship between professionals, patients and families, enabling new institutional practices and a participatory decision-making process ${ }^{(24)}$.

\section{CONCLUSION}

The decision-making process in end-of-life situations is difficult and depends on ethical issues related to moral, cultural and social values. The Brazilian policy is incipient, timid and inarticulate when it comes to end-of-life. In the context of ICU, this scenario is even more challenging; health professionals must incorporate the endof-life care and palliative care in assisting the patient and his family.

Knowledge of nurses, acquired by the practice of observation and the exercise of care in situations of end-of-life in ICU, must be redeemed and used by these professionals, enabling him to interventions that require ICU in decisionmaking. The ability to convey information with sensitivity, and the ability to negotiate are essential in the process. Knowing their own values and beliefs about life and death is also an important factor, as it implies the inclusion of nurses in the decision-making process.

Working with health professionals experience, facing the dying process, concerns studies for the improvement of these professionals about the end-of-life care. Thus, new studies on the subject are important and should be developed, including studies that result in training tools and 
evaluation of nursing professional skills within the ICU and ethical issues related to patient out of healing possibilities and his/her family, in order to achieve an innovative and effective way to meet the new demands of technology environments and end-of-life in the ICU.
The difficulty for the expansion of knowledge in the decision-making process, in end-of-life situations is related to the lack of care protocols guidelines for the care of patients with incurable diseases or nearing end-of-life, making care even more complex and challenging in these cases.

\section{RESUMO}

Objetivo: Identificar os fatores que influenciam o enfermeiro de Unidade de Terapia Intensiva no processo de tomada de decisão nas situações de final de vida. Método: Estudo de caso etnográfico que teve como referencial teórico a antropologia médica. Os dados foram coletados por meio de entrevista semiestruturada com 10 enfermeiros. Resultados: A análise temática indutiva possibilitou identificar quatro temas: O contexto cultural da Unidade de Terapia Intensiva: a tomada de decisão nas situaçôes de final de vida, Crenças e subjetividades no cuidado nas situaçôes de final de vida, Experiências profissionais e características do contexto de cuidado nas situaçôes de final de vida e Práticas de humanização nas situações de final de vida: o cuidado centrado no paciente e na família. Conclusão: A maturidade profissional, a habilidade para transmitir as informações e a capacidade para a negociação, estão diretamente relacionadas com a inserção do enfermeiro no processo de tomada de decisão.

\section{DESCRITORES}

Doente Terminal; Unidades de Terapia Intensiva; Enfermagem; Tomada de Decisões; Cultura; Antropologia.

\section{RESUMEN}

Objetivo: Identificar los factores que influencian al enfermero de Unidad de Cuidados Intensivos en el proceso de toma de decisión en las situaciones de final de vida. Método: Estudio de caso etnográfico que tuvo como marco de referencia teórico la antropología médica. Se recogieron los datos mediante entrevista semiestructurada con 10 enfermeros. Resultados: El análisis temático inductivo posibilitó identificar cuatro temas: El marco cultural de la Unidad de Cuidados Intensivos: la toma de decisión en las situaciones de final de vida, Creencias y subjetividades en el cuidado en las situaciones de final de vida, Experiencias profesionales y características del contexto de cuidado en las situaciones de final de vida y Prácticas de humanización en las situaciones de final de vida: el cuidado centrado en el paciente y la familia. Conclusión: La madurez profesional, la habilidad para transmitir las informaciones y la capacidad para la negociación están directamente relacionadas con la inserción del enfermero en el proceso de toma de decisión.

\section{DESCRIPTORES}

Enfermo Terminal; Unidades de Cuidados Intensivos; Enfermería; Toma de Decisiones; Cultura; Antropología.

\section{REFERENCES}

1. Capra F. O ponto de mutação. São Paulo: Cultrix; 2006.

2. Le Breton D. Antropologia do corpo e da modernidade. Petrópolis: Vozes; 2011.

3. Illich I. Medical nemesis: the expropriation of health. New York: Random House; 1976.

4. Davis-Floyd R. The technocratic, humanistic, and holistic paradigms of childbirth. Int J Gynaecol Obstet. 2001;75 Suppl 1:S5-23.

5. Poles K, Bousso RS. Dignified death: concept development involving nurses and doctors in pediatric intensive care units. Nurs Ethics. 2011;18(5):694-709.

6. Laraia RB. Cultura: um conceito antropológico. Rio de Janeiro: Jorge Zahar; 2008.

7. Noone J. Concept analysis of decision making. Nurs Forum. 2002;37(3):21-32.

8. Jensen $\mathrm{HI}$, Ammentorp J, Johannessen $\mathrm{H}$, Ørding $\mathrm{H}$. Challenges in end-of-life decisions in the intensive care unit: an ethical perspective. J Bioeth Inq. 2013;10(1):93-101.

9. Kimura AF, Merighi MAB. Estudo de caso. In: Merighi MAB, Praça NS, organizadoras. Abordagens teórico-metodológicas qualitativas: a vivência da mulher no período reprodutivo. Rio de Janeiro: Guanabara Koogan; 2003. p. 15-8.

10. Stake RE. Case studies. In: Denzin NK, Lincoln YS. Handbook of qualitative research. Thousand Oaks: Sage; 2000. p. 435-54.

11. Blasco JS. Estudio de casos. In: Batzan AA. Etnografia: metodologia cualitativa em la investigación sociocultural. Barcelona: Marcambo; 1995. p. 203-8.

12. Sandelowski M. Time and qualitative research. Res Nurs Health. 1999;22(1):79-87.

13. Patton MQ. Qualitative evaluation and research methods. Newbury Park: Sage; 2002.

14. Braun V, Clarke V. Using thematic analysis in psychology. Qual Res Psychol. 2006;3(2):77-101. 
15. Ayres L, Kavanaugh K, Knafl KA. Within-case and across-case approaches to qualitative data analysis. Qual Health Res. 2003;13(6):871-83.

16. Coombs M. The mourning after: the potential for critical care nurses to improve family outcome and experience in end of life care. Aust Crit Care. 2014;27(4):155-6.

17. Trajkovski S, Schmied V, Vickers M, Jackson D. Neonatal nurses' perspectives of family-centred care: a qualitative study. J Clin Nurs. 2012;21(17-18):2477-87.

18. Adams JA, Anderson RA, Docherty SL, Tulsky JA, Steinhauser KE, Bailey DE Jr. Nursing strategies to support family members of ICU patients at high risk of dying. Heart Lung. 2014;43(5):406-15.

19. Lind R, Lorem GF, Nortvedt P, Hevrøy O. Intensive care nurses' involvement in the end-of-life process-perspectives of relatives. Nurs Ethics. 2012;19(5):666-76.

20. Campos EA. Aspectos culturais e as práticas de cuidados em enfermagem. In: Nakamura E, Martin D, Santos JFG. Antropologia para enfermagem. Barueri: Manole; 2009. p. 59-81.

21. Penha RM, Silva MP. Significado de espiritualidade para a enfermagem em cuidados intensivos. Texto Contexto Enferm. 2012;21(2):260-8.

22. Institute for Patient and Family-Centered Care. Advancing the understanding and practice of patient- and family-centered care in all settings where individuals and families receive health care [Internet]. Bethesda; 1992-2014 [updated 2014; cited 2014 Sept 20]. Available from: http://www.ipfcc.org/index.html

23. Santos MR, Bousso RS, Vendramim P, Baliza MF, Misko MD, Silva L. The practice of nurses caring for families of pediatric inpatients in light of Jean Watson. Rev Esc Enferm USP [Internet]. 2014 [cited 2014 Sept 20];48(n.spe):80-6. Available from: http://dx.doi.org/10.1590/ S0080-623420140000600012

24. Menezes RA. Em busca da boa morte: antropologia dos cuidados paliativos. Rio de Janeiro: Garamond; 2008.

Funding Support: National Council for Scientific and Technological Development (CNPq). Process No 472463/2011-0. 